\title{
Unprecedented Reduction of 2,2'-Bipyrimidine in a One-Pot Synthesis of Neutral Rhenium(I)-Based Molecular Rectangles
}

\author{
Jing-Yun Wu ${ }^{\dagger}$ P. Thanasekaran, ${ }^{\dagger}$ Yi-Wei Cheng, ${ }^{\dagger}$ Chung-Chou Lee, ${ }^{\dagger}$ B. Manimaran,${ }^{\dagger}$ \\ T. Rajendran, ${ }^{\dagger}$ Rong-Tang Liao, ${ }^{\dagger}$ Gene-Hsiang Lee, ${ }^{\star}$ Shie-Ming Peng, ${ }^{\star}$ and \\ Kuang-Lieh $\mathrm{Lu}^{*}$, \\ Institute of Chemistry, Academia Sinica, Taipei 115, Taiwan, and Department of Chemistry, National \\ Taiwan University, Taipei 106, Taiwan
}

Received August 31, 2007

\begin{abstract}
Summary: An unprecedented partial reduction of 2,2'-bipyrimidine (bpym) occurred, affording the $\mathrm{H}_{6}$ bpym $^{2-}$ moiety, during the one-pot self-assembly of neutral Re(I)-based molecular rectangles and bimetallic products under solvothermal conditions. Their structures were unambiguously characterized by ${ }^{1} H$ NMR and single-crystal X-ray diffraction analyses, and their electrochemical, electronic absorption, and photoluminescent properties were studied. The reaction pathway was also investigated.
\end{abstract}

Transition-metal complexes containing a 2,2'-bipyrimidine (bpym) ligand are of great interest, due to their ability to absorb visible light as well as to store electrons in vacant $\pi^{*}$ levels: i.e., they act as "electron reservoirs" or as promoters of catalytic reactions and serve as a conduit for energy and electron transfer. $^{1-6}$ An interesting tetracationic bpym-containing rectangle, $\left[\left\{(\mathrm{CO})_{3} \operatorname{Re}(\mu \text {-bpym }) \operatorname{Re}(\mathrm{CO})_{3}\right\}_{2}(\mu \text {-bpy })_{2}\right]\left(\mathrm{CF}_{3} \mathrm{SO}_{3}\right)_{4}$, could be charged stepwise with the appropriate number of electrons, indicating the "electron reservoir" function of the molecule. ${ }^{2}$ Although bpym-containing metal complexes exhibit interesting photophysical and electrochemical properties, intermediates produced during their redox processes have never been char-

* To whom correspondence should be addressed. Fax: Int. code $+886-$ 2-27831237. E-mail: lu@ chem.sinica.edu.tw.

Academia Sinica.

$\doteqdot$ National Taiwan University.

(1) (a) Bar-Nahum, I.; Khenkin, A. M.; Neumann, R. J. Am. Chem. Soc. 2004, 126, 10236. (b) Rendina, L. M.; Puddephatt, R. J. Chem. Rev. 1997 97, 1735. (c) Periana, R. A.; Taube, D. J.; Gamble, S.; Taube, H.; Satoh, T.; Fujii, H. Science 1998, 280, 560.

(2) (a) Hartmann, H.; Berger, S.; Winter, R.; Fiedler, J.; Kaim, W. Inorg. Chem. 2000, 39, 4977. (b) Benkstein, K. D.; Hupp, J. T.; Stern, C. L. J. Am. Chem. Soc. 1998, 120, 12982.

(3) (a) Moore, J. T.; Chu, D.; Jiang, R.; Deluga, G. A.; Lukehart, C. M. Chem. Mater. 2003, 15, 1119. (b) Cai, Y.; Ellern, A.; Espenson, J. H. Inorg. Chem. 2005, 44, 2560. (c) Mylvaganam, K.; Bacskay, G. B.; Hush, N. S. J. Am. Chem. Soc. 1999, 121, 4633.

(4) (a) Rillema, D. P.; Allen, G.; Meyer, T. J.; Conrad, D. Inorg. Chem. 1983, 22, 1617. (b) Pavinato, R. A.; Walk, J. A.; McGuire, M. E. Inorg. Chem. 1993, 32, 4982. (c) Shavaleev, N. M.; Accorsi, G.; Virgili, D.; Bell, Z. R.; Lazarides, T.; Calogero, G.; Armaroli, N.; Ward, M. D. Inorg. Chem. 2005, 44, 61 .

(5) (a) De Munno, G.; Julve, M.; Verdaguer, M.; Bruno, G. Inorg. Chem. 1993, 32, 2215. (b) Cortes, R.; Urtiaga, M. K.; Lezama, L.; Pizarro, J. L.; Arriortua, M. I.; Rojo, T. Inorg. Chem. 1997, 36, 5016. (c) Marshall, S. R.; Incarvito, C. D.; Manson, J. L.; Rheingold, A. L.; Miller, J. S. Inorg. Chem. 2000, 39, 1969. (d) Ronco, S. E; Thompson, D. W.; Gahan, S. L.; Petersen, J. D. Inorg. Chem. 1998, 37, 2020.

(6) (a) Juris, A.; Campagna, S.; Bidd, I.; Lehn, J. M.; Ziessel, R. Inorg. Chem. 1988, 27, 4007. (b) Wrighton, M. S.; Morse, K. J. Am. Chem. Soc. 1974, 96, 998. (c) Adams, H.; Alsindi, W. Z.; Davies, G. M.; Duriska, M. B.; Easun, T. L.; Fenton, H. E.; Herrera, J. M.; George, M. W.; Ronayne, K. L.; Sun, X. Z.; Towrie, M.; Ward, M. D. Dalton Trans. 2006, 39. (d) Van Wallendael, S.; Shaver, R. J.; Rillema, D. P.; Yoblinski, B. J.; Stathis, M.; Guarr, T. F. Inorg. Chem. 1990, 29, 1761. acterized by solid-state data. As part of our ongoing efforts in the design and synthesis of functional metallacyclic materials, ${ }^{7}$ we report herein on the unprecedented partial reduction of $2,2^{\prime}$ bipyrimidine during the one-pot self-assembly of neutral $\operatorname{Re}(\mathrm{I})$ based molecular rectangles under solvothermal conditions. The partially reduced 2,2'-bipyrimidine, $\mathrm{H}_{6} \mathrm{bpym}^{2-}$, was stabilized by the rectangles, and the structures were unambiguously characterized by ${ }^{1} \mathrm{H}$ NMR and single-crystal X-ray diffraction analyses. The unusual transformation of the bpym ligand under hydrothermal conditions, the structural characterization of the partially reduced $\mathrm{H}_{6}$ bpym ${ }^{2-}$ moiety, and the one-pot synthesis of neutral $\operatorname{Re}(\mathrm{I})$-based rectangles are the features of this work.

\section{Results and Discussion}

Observation of Partial Reduction of 2,2'-Bipyrimidine. The one-pot self-assembly of the molecular rectangles $\left[\left\{(\mathrm{CO})_{3} \operatorname{Re}(\mu\right.\right.$ $\mathrm{H}_{6}$ bpym $\left.\left.) \operatorname{Re}(\mathrm{CO})_{3}\right\}_{2}(\mu \text {-L })_{2}\right]\left(\mathbf{1 a}, \mathrm{L}=\right.$ pyrazine; $\mathbf{1 b}, \mathrm{L}=4,4^{\prime}$ bipyridine) from $\operatorname{Re}_{2}(\mathrm{CO})_{10}, 2,2^{\prime}$-bipyrimidine (bpym), and pyrazine (pz) or $4,4^{\prime}$-bipyridine (bpy) at $160{ }^{\circ} \mathrm{C}$ was achieved in high yields (Scheme 1). The ${ }^{1} \mathrm{H}$ NMR spectrum of $\mathbf{1 b}$ showed two sets of signals at $\delta 8.59$ and 7.88 ppm originating from the $\mathrm{H}^{3}$ and $\mathrm{H}^{2}$ protons of the coordinated $4,4^{\prime}$-bipyridine. To our surprise, the aromatic proton signals of 2,2'-bipyrimidine disappeared, while the peaks at $\delta 3.68,1.93$, and $1.82 \mathrm{ppm}$, corresponding to aliphatic protons, were observed in the upfield region of the spectrum. This implies that an unusual reduction of 2,2'-bipyrimidine would likely take place during the course of the reaction. The ${ }^{1} \mathrm{H}$ NMR spectrum of $\mathbf{1 a}$ had a similar pattern. Both products were soluble in $\mathrm{CH}_{2} \mathrm{Cl}_{2}$, DMSO, DMF, THF, and acetone.

Solid-State Evidence for the Partially Reduced 2,2'-Bipyrimidine. A single-crystal X-ray diffraction analysis was undertaken to examine the exact coordination characteristics of the reduced bipyrimidine ligand within the architecture. The structure of 1a has a rectangular architecture in which two $(\mathrm{CO})_{3} \operatorname{Re}-(\mathrm{pz})-\mathrm{Re}(\mathrm{CO})_{3}$ edges are bridged by two reduced $2,2^{\prime}$ bipyrimidine moieties with a cavity dimension of $5.79 \times 7.31$ $\AA$ (Figure 1). It is noteworthy that C7, C8, C9, C12, C13, and $\mathrm{C} 14$ of the 2,2'-bipyrimidine are reduced, with $\mathrm{C}-\mathrm{C}$ singlebond lengths $(\mathrm{C} 7-\mathrm{C} 8, \mathrm{C} 12-\mathrm{C} 13$, etc.) ranging from 1.485(10) to $1.514(11) \AA$ and an $\mathrm{sp}^{3}$ configuration $\left(110.8(7)-112.2(6)^{\circ}\right)$ in the reduced rings. This was corroborated by the observation of nonequivalent aliphatic proton signals for the reduced $2,2^{\prime}$ bipyrimidine in the ${ }^{1} \mathrm{H}$ NMR spectrum. The highly conjugated

(7) (a) Manimaran, B.; Rajendran, T.; Lu, Y. L.; Lee, G. H.; Peng, S. M.; Lu, K. L. J. Chem. Soc., Dalton Trans. 2001, 515. (b) Manimaran, B.; Thanasekaran, P.; Rajendran, T.; Lin, R. J.; Chang, I. J.; Lee, G. H.; Peng, S. M.; Rajagopal, S.; Lu, K. L. Inorg. Chem. 2002, 41, 5323. 
Scheme 1. Trapping of Partially Reduced 2,2'-Bipyrimidine in the Self-Assembly of Re(I)-Based Rectangles 1a,b and Bimetallic Complex 2

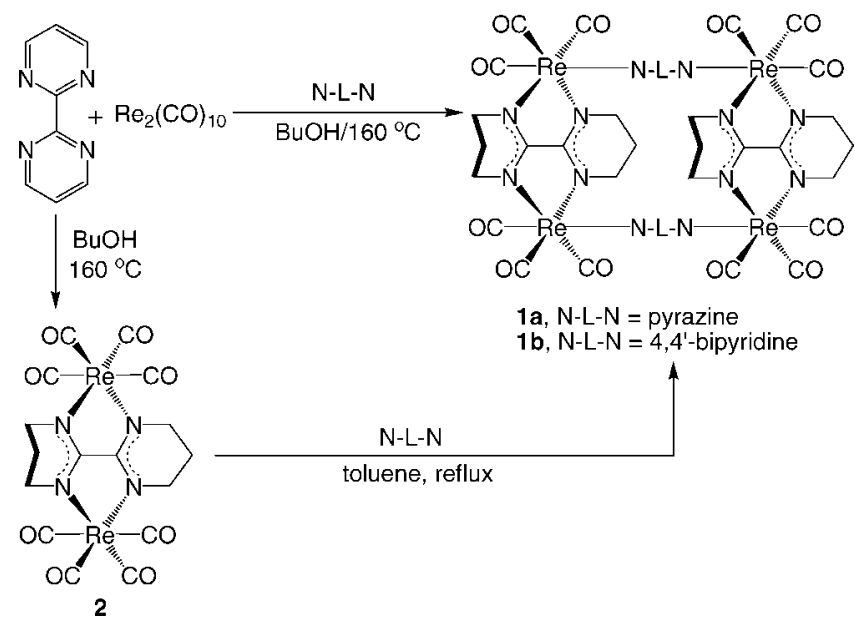

$\mathrm{N}_{2} \mathrm{CCN}_{2}$ core remains intact and is coordinated to two rhenium metal centers as a bridging bis-chelated ligand. It is significant that the bond lengths for $\mathrm{Re}-\mathrm{N}\left(\mathrm{H}_{6} \mathrm{bpym}^{2-}\right)(2.146(6)-2.155(5)$ $\AA$ ) are shorter than those of $\mathrm{Re}-\mathrm{N}(\mathrm{pz})(2.226(5)-2.248(5) \AA)$, suggesting a negative charge on the $\mathrm{N}$ atoms of $\mathrm{H}_{6} \mathrm{bpym}^{2-}$.

Compound $\mathbf{1 b}$ also adopts a rectangular architecture (Figure $\mathrm{S} 1$; see the Supporting Information), where the 2,2'-bipyrimidine is reduced and possesses characteristics similar to those of $\mathbf{1 a}$ with a slight disorder of the reduced carbon atoms, providing unambiguous solid-state evidence of the unprecedented reduction of the bpym ligand.

Study of the Reaction Pathway. It appears that the 2,2'bipyrimidine moiety in the solid-state structures of both $\mathbf{1 a}$ and 1b are partially reduced while the pyrazine or/and $4,4^{\prime}$-bipyridine remains intact. In order to understand the details of the reduction of 2,2'-bipyrimidine during the self-assembly process, the reaction of $\operatorname{Re}_{2}(\mathrm{CO})_{10}$ with $2,2^{\prime}$-bipyrimidine in butanol in the

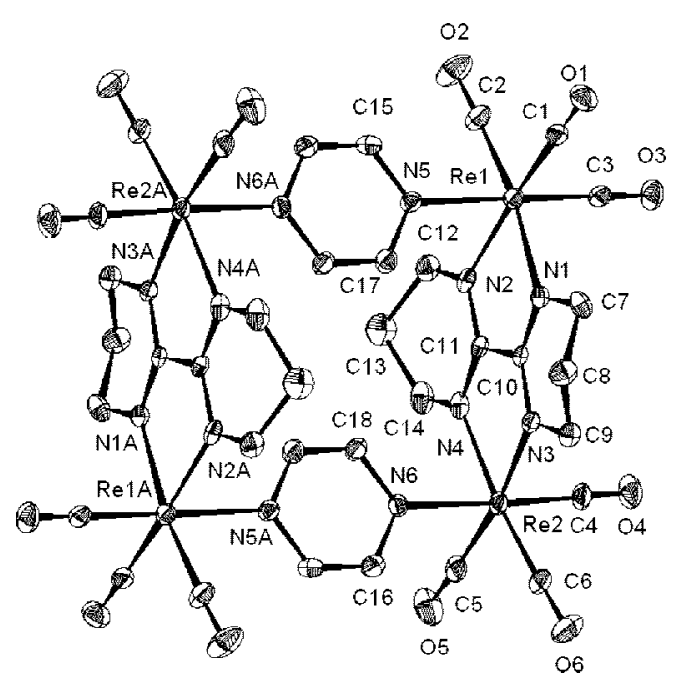

Figure 1. ORTEP diagram of 1a with thermal ellipsoids at the 50\% probability level. Hydrogen atoms are omitted for clarity. Selected bond lengths ( $)$ : Re1-N1, 2.148(5); Re1-N2, 2.149(6); Re1-N5, 2.248(5); Re1-C1, 1.929(8); Re1-C2, 1.923(7); Re1-C3, 1.915(7); Re2-N3, 2.155(5); Re2-N4, 2.146(6); Re2-N6, 2.226(5); Re2-C4, 1.911(7); Re2-C5, 1.911(8); Re2-C6, 1.910(5); C10-C11, 1.495(8); $\mathrm{N} 1-\mathrm{C} 10,1.325(8)$; N1-C7, 1.470(8); C7-C8, 1.511(9); C8-C9, 1.485(10); N3-C9, 1.477(8); N3-C10, 1.323(8); N2-C11, 1.324(8); N2-C12, 1.480(8); C12-C13, 1.489(10); C13-C14, 1.514(11); N4-C14, 1.474(9); N4-C11, 1.323(8). absence of difunctional ligands (pz or bpy) under solvothermal conditions was therefore undertaken (Scheme 1) and the deepbrown bimetallic compound 2 was obtained in $65 \%$ yield. In this reaction, the 2,2'-bipyrimidine ligand underwent a partial hydrogenation and was stabilized by the rhenium metal center to form compound $\mathbf{2}$. The FAB-mass spectrum of $\mathbf{2}$ showed a molecular ion peak at $m / z, 760.2\left(\mathbf{M}^{+}\right)$. The ${ }^{1} \mathrm{H}$ NMR spectrum showed that the signals at $\delta 3.52$ and $1.81 \mathrm{ppm}$ corresponded to the partially reduced $2,2^{\prime}$-bipyrimidine protons, implying that the reduction occurred at this stage of the reaction.

The structure of $\mathbf{2}$ was characterized by a single-crystal X-ray diffraction analysis, and the ORTEP diagram is shown in Figure 2. The 2,2'-bipyrimidine ligand was reduced, similar to that of compound 1. The lengths of intra-ring $\mathrm{C}-\mathrm{C}$ single bonds $(1.483(6)-1.486(6) \AA), \mathrm{C}-\mathrm{N}\left(\mathrm{H}_{6} \mathrm{bpym}^{2-}\right)$ bonds $(1.313(5)-$ $1.321(5) \AA)$ in the delocalized $\mathrm{N}_{2} \mathrm{CCN}_{2}$ core, and other $\mathrm{C}-\mathrm{N}\left(\mathrm{H}_{6}\right.$ bpym $\left.^{2-}\right)$ bonds $(1.460(4)-1.464(4) \AA)$, as well as the $\mathrm{Re}-\mathrm{N}\left(\mathrm{H}_{6}\right.$ bpym $\left.^{2-}\right)$ bonds $(2.150(3)-2.158(3) \AA)$, bear characteristics similar to those of $\mathbf{1 a}, \mathbf{b}$.

Treatment of $\mathbf{2}$ with 4,4'-bipyridine afforded compound $\mathbf{1 b}$ in high yield, indicating that $\mathbf{2}$ is the precursor of $\mathbf{1 b}$. This confirms that the reduction of 2,2'-bipyrimidine takes place in an early stage of the reaction, which was stabilized by the product 2 . The latter then reacted with the bipyridyl ligand (bpy) to produce the final product $\mathbf{1 b}$.

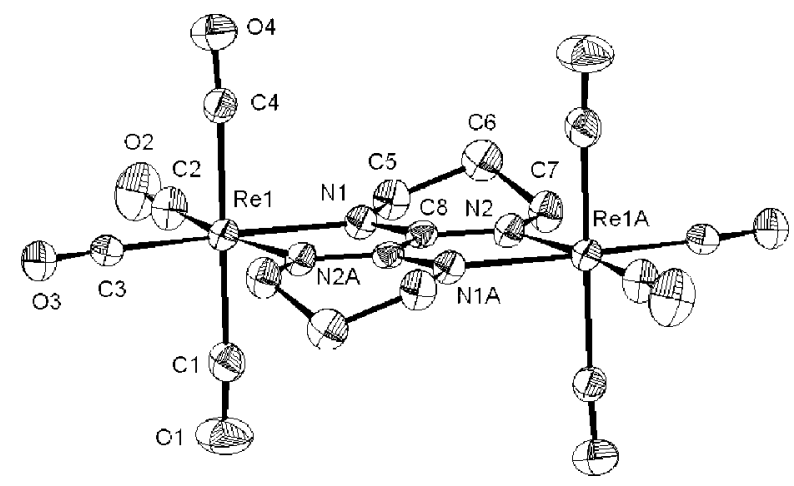

Figure 2. ORTEP diagram of $\mathbf{2}$ with thermal ellipsoids at the $30 \%$ probability level. Hydrogen atoms are omitted for clarity. Selected bond lengths $(\AA): \operatorname{Re} 1-C 1,1.985(5)$; Re1-C2, 1.919(5); $\mathrm{Re} 1-\mathrm{C} 3,1.934(4) ; \operatorname{Re} 1-\mathrm{C} 4,2.005(5) ; \operatorname{Re} 1-\mathrm{N} 1,2.150(3)$; $\mathrm{Re} 1-\mathrm{N} 2,2.158(3)$; C8-C8A, 1.489(6); N1-C8, 1.321(5); N1-C5, 1.464(4); C5-C6, 1.483(6); C6-C7, 1.486(6); N2-C7, 1.460(4); N2-C8, 1.313(5). 
The reaction pathway of the partial hydrogenation of 2,2'bipyrimidine is of particular interest. The results of the structural analysis indicate that the reduction occurs during formation of compound 2. In the literature, rhenium metal centers are not commonly used for hydrogenation reactions, but several examples of the hydrogenation of organic compounds by rhenium metal complexes have been reported. ${ }^{8}$ The enantioselective reduction of imines catalyzed by a rhenium $(\mathrm{V})$-oxo complex has also been reported. ${ }^{8 \mathrm{a}}$ In addition, rhenium carbonyl complexes have been observed to facilitate hydrogenation of ynamine and imines or catalyze hydrogenation of 1-hexene. ${ }^{8 \mathrm{~b}-\mathrm{d}}$ Although the nature of the hydrogenation of bpym and the formation of $\mathbf{2}$ is not yet clear, the results to date suggest that metal binding is a prerequisite for the observed hydrogenation of bpym. The initial metal-binding reaction between $\operatorname{Re}_{2}(\mathrm{CO})_{10}$ and bpym may yield a $\operatorname{Re}_{2}{ }_{2}\left(\right.$ bpym $\left.^{2-}\right)$ intermediate, as suggested by electrochemical evidence, ${ }^{9}$ that then undergoes solventpromoted $\mathrm{e}^{-}$and $\mathrm{H}^{+}$transfer to yield the observed species. The transformation of bpym and $\operatorname{Re}_{2}(\mathrm{CO})_{10}$ to $\mathbf{2}$ involves transfer of $8 \mathrm{e}^{-}$and $6 \mathrm{H}^{+}$. It is apparent that the rhenium atoms cannot be the only reductant of bpym, as they can afford only two of the eight electrons necessary for the formation of $\mathrm{H}_{6} \mathrm{bpym}^{2-}$. Therefore, the solvent, $\mathrm{BuOH}$, may participate in the redox reaction, supplying electrons and protons. The reduction of imidorhenium(V) complexes to amidorhenium(III) species along with the oxidation of ethanol solvent has been reported. ${ }^{8 f}$ As a consequence, the $\operatorname{Re}_{2}{ }_{2}\left(\mathrm{bpym}^{2-}\right)$ intermediate would readily transform to the observed product $\mathbf{2}$ in high yield.

In comparison, an interesting bpym-containing tetracationic rectangle, $\left[\left\{(\mathrm{CO})_{3} \operatorname{Re}(\mu \text {-bpym }) \operatorname{Re}(\mathrm{CO})_{3}\right\}_{2}(\mu \text {-bpy })_{2}\right]\left(\mathrm{CF}_{3} \mathrm{SO}_{3}\right)_{4}$, is synthesized via a stepwise fashion by first creating a bimetallic edge with a difunctional chelating bpym bridge and then by adding bpy ligand. ${ }^{2 \mathrm{~b}}$ Nevertheless, compounds $\mathbf{1 a}, \mathbf{b}$, which contain reduced $\mathrm{H}_{6} \mathrm{bpym}^{2-}$, were synthesized in a one-pot reaction, under solvothermal conditions, forming the neutral rectangular products. The unprecedented reduction of the bpym ligand makes the one-pot synthesis of neutral molecular rectangles possible. It is noteworthy that the development of one-step syntheses for the preparation of molecular rectangles is of great interest, as the reaction of a mixture of metal precursors and two rigid ligands tends to result in the two corresponding molecular squares. ${ }^{10}$

Electrochemical Studies. The measured cyclic voltammetric data for the rectangles 1a,b are summarized in Table 1. Cyclic voltammograms (CVs) of $\mathbf{1 a , b}$ in THF display four reduction waves, which correspond to the stepwise reduction reactions of the $\mathrm{N}-\mathrm{L}-\mathrm{N}$ ligands (pyrazine in $\mathbf{1 a}$ and bpy in $\mathbf{1 b}$; Figure 3). Similar behavior has been noted for the compounds $\left(\left[\operatorname{Re}(\mathrm{CO})_{3}\right]_{2} \mathrm{BiBzIm}\right)_{2}(\mu \text {-bpy })_{2}\left(\mathrm{BiBzIm}=2,2^{\prime}\right.$-bisbenzimida-

(8) (a) Nolin, K. A.; Ahn, R. W.; Toste, F. D. J. Am. Chem. Soc. 2005 , 127, 12462. (b) Adams, R. D.; Chen, G.; Yin, J. Organometallics 1991, 10, 2087. (c) Lin, X. Y.; Venkatesan, K.; Schmalle, H. W.; Berke, H. Organometallics 2004, 23, 3153. (d) Haupt, H. J.; Wittbecker, R.; Flörke, U. J. Organomet. Chem. 1996, 518, 213. (e) Broadbent, H. S.; Campbell, G. C.; Bartley, W. J.; Johnson, J. H. J. Org. Chem. 1959, 24, 1847. (f) Suing, A. L.; Dewan, C. R.; White, P. S.; Thorp, H. H. Inorg. Chem. 2000, 39,6080

(9) (a) Kaim, W.; Kohlmann, S. Inorg. Chem. 1990, 29, 2909. (b) Sahai, R.; Rillema, D. P.; Shaver, R.; Wallendael, S. V.; Jackman, D. C.; Boldaji, M. Inorg. Chem. 1989, 28, 1022.

(10) (a) Slone, R. V.; Benkstein, K. D.; Be'langer, S.; Hupp, J. T.; Guzei, I. A.; Rheingold, A. L. Coord. Chem. Rev. 1998, 171, 221. (b) Holliday, B. J.; Mirkin, C. A. Angew. Chem., Int. Ed. 2001, 40, 2022. (c) Thanasekaran, P.; Liao, R. T.; Liu, Y. H.; Rajendran, T.; Rajagopal, S.; Lu, K. L. Coord. Chem. Rev. 2005, 249, 1085.
Table 1. Redox Potentials of Neutral Re(I)-Based Rectangles 1a,b in THF $^{a}$

\begin{tabular}{cccccc}
\hline & & \multicolumn{4}{c}{$E_{1 / 2}{ }^{\text {red }}, \mathrm{V}$} \\
\cline { 3 - 6 } complex & $E_{1 / 2}{ }^{\text {ox }}, \mathrm{V}$ & $E_{1 / 2}{ }^{0 /-}$ & $E_{1 / 2}{ }^{-/ 2-}$ & $E_{1 / 2}{ }^{2-/ 3-}$ & $E_{1 / 2}{ }^{3-/ 4-}$ \\
\hline 1a & 0.49 & -1.44 & -1.66 & -2.64 & -3.00 \\
1b & 0.47 & -1.67 & -1.89 & -2.55 & -2.80
\end{tabular}

${ }^{a}$ In $\mathrm{THF} / 0.1 \mathrm{M} \mathrm{Bu}_{4} \mathrm{NPF}_{6}$ at $100 \mathrm{mV} / \mathrm{s}$ scan rate; potentials in $\mathrm{V}$ vs $\mathrm{Fc} / \mathrm{Fc}^{+}$.
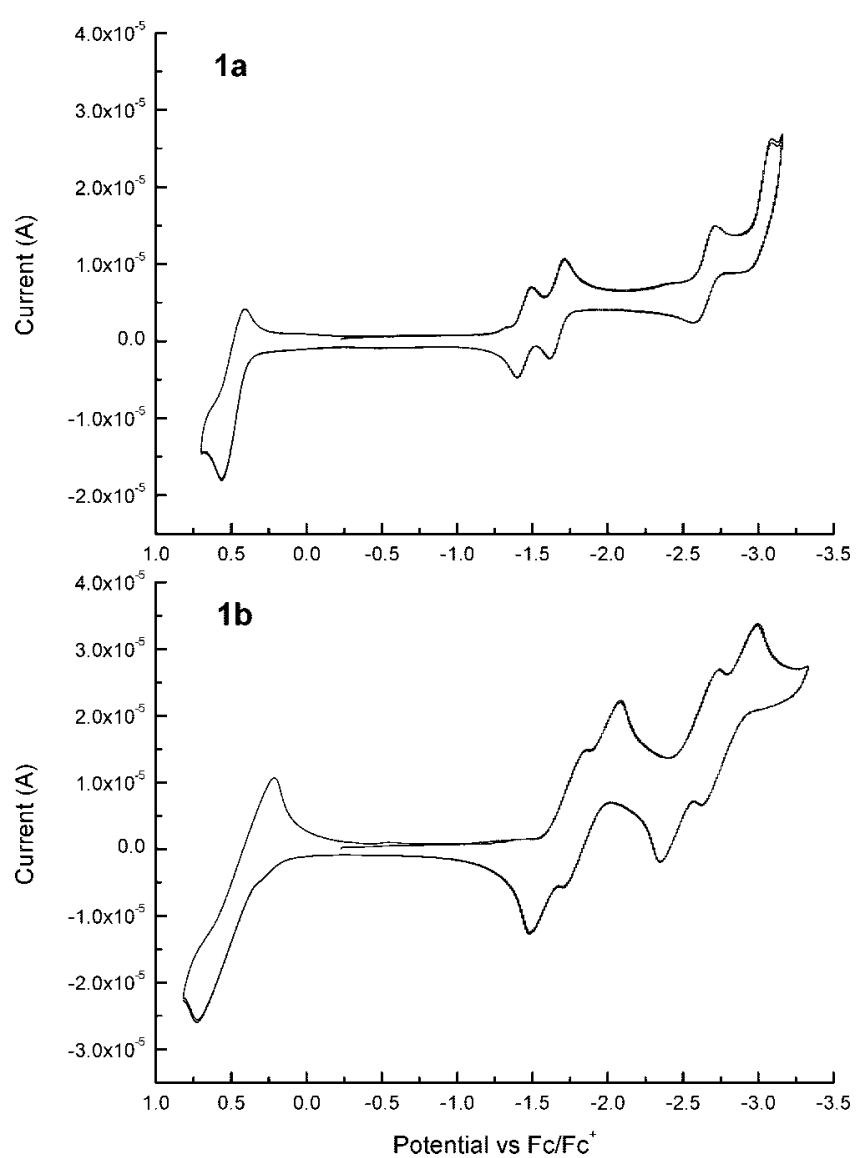

Figure 3. Cyclic voltammograms of $\mathbf{1 a}$ (top) and $\mathbf{1 b}$ (bottom) in THF with $0.1 \mathrm{M} \mathrm{Bu}_{4} \mathrm{NPF}_{6}$ as the supporting electrolyte.

zolate) and $\left(\left[\operatorname{Re}(\mathrm{CO})_{3}\right]_{2} \mathrm{BiBzIm}\right)_{2}(\mu-\mathrm{pz})_{2} \cdot{ }^{11,12}$ The metal coordination of the ligands shifts the reduction potential to less negative values via electrostatic stabilization of the reduced forms of the ligands..$^{2 \mathrm{a}, 11,12}$ Compounds 1a,b also displayed a quasi-reversible oxidation wave near $0.5 \mathrm{~V}$, which is likely associated with oxidation of the Re centers. Metal complexes containing a bpym ligand are of great interest due to their ability to act as "electron reservoirs" or to serve as conduits for energy and electron transfer. ${ }^{1-6}$ The results of the electrochemical analysis of 1a,b demonstrate a good signature (absence of bpym responses) of coordination by reduced bpym. Since $\mathrm{H}_{6}$ bpym $^{2-}$ contains two additional electronegative nitrogen atoms compared to bpym, the species is not easily reduced again. These results indicate significantly different characteristics between reduced $\mathrm{H}_{6}$ bpym $^{2-}$ and nonreduced bpym ligands, compared to those of the tetracationic rectangle $\left[\left\{(\mathrm{CO})_{3} \operatorname{Re}(\mu \text {-bpym }) \operatorname{Re}(\mathrm{CO})_{3}\right\}_{2}(\mu\right.$ bpy $\left.)_{2}\right]\left(\mathrm{CF}_{3} \mathrm{SO}_{3}\right)_{4} \cdot{ }^{2 \mathrm{a}}$

(11) Dinolfo, P. H.; Williams, M. E.; Stern, C. L.; Hupp, J. T. J. Am. Chem. Soc. 2004, 126, 12989.

(12) Dinolfo, P. H.; Benkstein, K. D.; Stern, C. L.; Hupp, J. T. Inorg. Chem. 2005, 44, 8707. 
Electronic Absorption Spectra and Luminescence Properties. UV-visible absorption spectra for $\mathbf{1 a}, \mathbf{b}$ and $\mathbf{2}$ in $\mathrm{CH}_{2} \mathrm{Cl}_{2}$ show that the absorption bands in the high-energy region $(230-351 \mathrm{~nm})$ correspond to the ligand-centered (LC) transition (Figure S3; see the Supporting Information). The broad absorption bands at 563 and $466 \mathrm{~nm}$ for 1a,b, respectively, correspond to the $\mathrm{d} \pi(\mathrm{Re}) \rightarrow \pi^{*}(\mathrm{pz}$ for $\mathbf{1 a}$, bpy for $\mathbf{1 b})$ transition. $^{12}$

Complexes 1a,b show photoluminescence behavior upon excitation of their metal-to-ligand charge-transfer transitions (MLCT) band in a solution of $\mathrm{CH}_{2} \mathrm{Cl}_{2}$ (Figure S4; see the Supporting Information). The broad and structureless emission bands at 685 and $605 \mathrm{~nm}$ for $\mathbf{1 a}, \mathbf{b}$, respectively, feature a ${ }^{3}$ MLCT character. In the solid state, $\mathbf{1 a}, \mathbf{b}$ exhibit photoluminescence bands at 711 and $627 \mathrm{~nm}$, respectively, on excitation at 430 and $390 \mathrm{~nm}$, respectively, at ambient temperature (Figure S5; see the Supporting Information). These structureless emission bands in the visible region are assigned to ${ }^{3}$ MLCT. ${ }^{13}$ To our knowledge, there are only a few Re-based molecular rectangles that are emissive at room temperature. , $^{, 14}$

\section{Conclusion}

This work is notable for the fact that the 2,2'-bipyrimidine (bpym) ligand was reduced in situ to a nonaromatic bicycle $\left(\mathrm{H}_{6} \mathrm{bpym}^{2-}\right)$ in the synthesis of neutral rhenium(I) molecular rectangles, 1a,b. The partially reduced $\mathrm{H}_{6}$ bpym ${ }^{2-}$ moiety was stabilized in the products, and its structure was unambiguously characterized by ${ }^{1} \mathrm{H}$ NMR and single-crystal X-ray diffraction analyses. The reduction of the bpym ligand resulted in the successful one-pot synthesis of the neutral molecular rectangles.

\section{Experimental Section}

Materials and General Methods. Reagents were used as received without further purification. The solvents used in this study were of spectroscopic grade. IR spectra were recorded on a PerkinElmer 882 FT-IR spectrophotometer. ${ }^{1} \mathrm{H}$ NMR spectra were recorded on Bruker AC 300 and AMX-400 FT-NMR spectrometers. Elemental analyses were performed using a Perkin-Elmer 2400 CHN elemental analyzer. FAB-MS data were obtained using a JMS700 double-focusing mass spectrometer. The electronic absorption spectra were obtained on a Hewlett-Packard 8453 spectrophotometer at room temperature in a $1 \mathrm{~cm}$ quartz cell. Fluorescence spectra

(13) (a) Casper, J. V.; Meyer, T. J. J. Phys. Chem. 1983, 87, 952. (b) Wang, Y.; Hauser, B. T.; Rooney, M. M.; Burton, R. D.; Schanze, K. S. J. Am. Chem. Soc. 1993, 115, 5675. (c) Yam, V. W. W.; Lau, V. C. Y.; Wu, L. X. J. Chem. Soc., Dalton Trans. 1998, 1461. and references cited therein. (d) Guerrero, J.; Piro, O. E.; Wolkan, E.; Feliz, M. R.; Ferraudi, G.; Moya, S. A. Organometallics 2001, 20, 2842.

(14) (a) Woessner, S. M.; Helms, J. B.; Shen, Y.; Sullivan, B. P. Inorg. Chem. 1998, 37, 5406. (b) Rajendran, T.; Manimaran, B.; Lee, F.-Y.; Lee, G.-H.; Peng, S.-M.; Wang, C. M.; Lu, K.-L. Inorg. Chem. 2000, 39, 2016. were recorded on a Hitachi F4500 spectrometer. Cyclic voltammetry was carried out at a $100 \mathrm{mV} / \mathrm{s}$ scan rate in anhydrous THF/0.1 M $\mathrm{Bu}_{4} \mathrm{NPF}_{6}$ at room temperature, using a three-electrode configuration (glassy-carbon electrode, platinum counter electrode, $\mathrm{Ag} / \mathrm{AgNO}_{3}$ reference electrode) and a $\mathrm{CHI} 621 \mathrm{~B}$ electrochemical analyzer under deaerated conditions.

Synthesis of $\left[\left\{(\mathrm{CO})_{3} \operatorname{Re}\left(\mu-\mathrm{H}_{6} \mathrm{bpym}\right) \operatorname{Re}(\mathrm{CO})_{3}\right\}_{2}(\mu-\mathrm{pz})_{2}\right]$ (1a). The reaction of a mixture of $\operatorname{Re}_{2}(\mathrm{CO})_{10}(65.3 \mathrm{mg}, 0.10 \mathrm{mmol}), 2,2^{\prime}-$ bipyrimidine (15.6 $\mathrm{mg}, 0.10 \mathrm{mmol})$, and pyrazine $(8.0 \mathrm{mg}, 0.10$ $\mathrm{mmol}$ ) in $8 \mathrm{~mL}$ of butanol was carried out in a Teflon-lined stainless steel bomb at $160{ }^{\circ} \mathrm{C}$ for $48 \mathrm{~h}$. The solution was decanted, and the purple crystals were washed with butanol and hexane several times and then dried. The crystals were of X-ray quality and were characterized spectroscopically. Yield: 67\%. IR (THF): $v_{\mathrm{CO}} 2021$ (s), 2012 (s), 1918 (vs), 1894 (vs) cm ${ }^{-1}$. ${ }^{1} \mathrm{H}$ NMR (400 MHz, $\left.\mathrm{CH}_{2} \mathrm{Cl}_{2}-d_{2}\right): \delta 8.68(\mathrm{~s}, 8 \mathrm{H}, \mathrm{pz}), 3.61\left(\mathrm{~m}, 16 \mathrm{H}, \mathrm{H}^{4}, \mathrm{H}_{6} \mathrm{bpym}^{2-}\right), 1.89$, $1.78\left(\mathrm{~m}, 8 \mathrm{H}, \mathrm{H}^{5}, \mathrm{H}^{5^{\prime}}, \mathrm{H}_{6}\right.$ bpym $\left.{ }^{2-}\right)$. Anal. Calcd for $\mathrm{C}_{36} \mathrm{H}_{32} \mathrm{~N}_{12} \mathrm{O}_{12} \mathrm{Re}_{4}$ : C, 27.55; H, 2.06; N, 10.71. Found: C, 27.58; H, 2.17; N, 10.53 .

Synthesis of $\left[\left\{(\mathrm{CO})_{3} \operatorname{Re}\left(\mu-\mathrm{H}_{6} \mathrm{bpym}\right) \operatorname{Re}(\mathrm{CO})_{3}\right\}_{2}(\mu \text {-bpy })_{2}\right](1 \mathrm{~b})$. Orange rectangular $\mathbf{1 b}$ was obtained by following a procedure similar to that for 1a using 4,4'-bipyridine instead of pyrazine. Yield: $79 \%$. IR (THF): $v_{\mathrm{CO}} 2008$ (s), 2002 (s), 1894 (s), 1888 (vs) cm ${ }^{-1} \cdot{ }^{1} \mathrm{H}$ NMR (400 MHz, $\left.\mathrm{CH}_{2} \mathrm{Cl}_{2}-d_{2}\right): \delta 8.59\left(\mathrm{dd}, J=5.2,1.6 \mathrm{~Hz}, 8 \mathrm{H}, \mathrm{H}^{3}\right.$, bpy), $7.88\left(\mathrm{dd}, J=5.2,1.6 \mathrm{~Hz}, 8 \mathrm{H}, \mathrm{H}^{2}, \mathrm{bpy}\right), 3.68\left(\mathrm{~m}, 16 \mathrm{H}, \mathrm{H}^{4}\right.$, $\mathrm{H}_{6}$ bpym $^{2-}$ ), 1.93, 1.82 (m, 8H, $\mathrm{H}^{5}, \mathrm{H}^{5^{\prime}}, \mathrm{H}_{6}$ bpym $^{2-}$ ). FAB-MS: $\mathrm{m} / \mathrm{z}$ $1722.87\left(\mathrm{M}^{+}\right)$. Anal. Calcd for $\mathrm{C}_{48} \mathrm{H}_{40} \mathrm{~N}_{12} \mathrm{O}_{12} \mathrm{Re}_{4}$ : C, 33.48; H, 2.34; N, 9.76. Found: C, 33.96; H, 2.51; N, 9.39.

Synthesis of $\left[(\mathrm{CO})_{4} \operatorname{Re}\left(\mu-\mathrm{H}_{6} \mathrm{bpym}\right) \operatorname{Re}(\mathrm{CO})_{4}\right]$ (2). The reddish brown compound $\mathbf{2}$ was obtained by following a procedure similar to that for $\mathbf{1 a}$ in the absence of pyrazine or 4,4'-bipyridine. Yield: 65\%. IR $\left(\mathrm{CH}_{2} \mathrm{Cl}_{2}\right): v_{\mathrm{CO}} 2096$ (s), 1997 (vs), 1965 (vs), 1923 (vs), $1888(\mathrm{~m}) \mathrm{cm}^{-1} .{ }^{1} \mathrm{H}$ NMR $\left(400 \mathrm{MHz}, \mathrm{CH}_{2} \mathrm{Cl}_{2}-d_{2}\right): \delta 3.52(\mathrm{~m}, 8 \mathrm{H}$, $\mathrm{H}^{4}, \mathrm{H}_{6}$ bpym $\left.^{2-}\right), 1.81\left(\mathrm{~m}, 4 \mathrm{H}, \mathrm{H}^{5}, \mathrm{H}^{5^{\prime}}, \mathrm{H}_{6}\right.$ bpym $\left.^{2-}\right)$. FAB-MS: $m / z$ $760.2\left(\mathrm{M}^{+}\right)$; Anal. Calcd for $\mathrm{C}_{16} \mathrm{H}_{12} \mathrm{~N}_{4} \mathrm{O}_{8} \mathrm{Re}_{2}$ : C, 25.26; H, 1.59; N, 7.37. Found: C, 26.23; H, 1.74; N, 7.00.

Synthesis of $\mathbf{1 b}$ from 2 . To a toluene solution $(20 \mathrm{~mL})$ of $\left[(\mathrm{CO})_{4^{-}}\right.$ $\operatorname{Re}\left(\mu_{4}-\mathrm{H}_{6}\right.$ bpym $\left.) \operatorname{Re}(\mathrm{CO})_{4}\right](2 ; 76.2 \mathrm{mg}, 0.10 \mathrm{mmol})$ was added $4,4^{\prime}-$ bipyridine $(16.0 \mathrm{mg}, 0.10 \mathrm{mmol})$, and the mixture was refluxed for 1 day in a $100 \mathrm{~mL}$ three-necked round-bottom flask at $110{ }^{\circ} \mathrm{C}$. The resulting orange product $\mathbf{1 b}$ was collected by filtration and dried under vacuum. Yield: 59\% (102.1 mg, $0.06 \mathrm{mmol}$ ).

Acknowledgment. We thank Academia Sinica and the National Science Council of Taiwan for financial support.

Supporting Information Available: Text, figures, tables, and CIF files giving details of the X-ray structural analysis and crystallographic data for $\mathbf{1 a}, \mathbf{b}$ and $\mathbf{2}$, a cyclic voltammogram of $\mathbf{2}$, UV-vis absorption spectra of $\mathbf{1 a}, \mathbf{b}$ and $\mathbf{2}$, and photoluminescence spectra of 1a,b. This material is available free of charge via the Internet at http://pubs.acs.org.

OM700873X 